\title{
Steroid dan Lignan dari Kayu Batang Durio oxleyanus (Malvaceae)
}

\section{Rudiyansyah $^{1}$}

\author{
${ }^{1}$ Jurusan Kimia, Fakultas Matematika dan Ilmu Pengetahuan Alam, Universitas Tanjungpura, \\ Jl. Prof. Dr. H. Hadari Nawawi, Pontianak 78124, Kalimantan Barat \\ Email : ryansyah_2000@yahoo.co.uk
}

\begin{abstract}
Abstrak
Pencarian senyawa metabolit sekunder dari ekstrak aseton kayu batang tumbuhan Durio oxleyanus Griff telah menghasilkan senyawa steroid androst-1,4-dien-3,7-dion (1) beserta dua senyawa lignan yaitu boehmenan (2) dan boehmenan X (3) dan fraksidin (4). Struktur kimia senyawa hasil isolasi tersebut dielusidasi berdasarkan data spektroskopi dan perbandingan dengan data spektrum yang telah dilaporkan sebelumnya.
\end{abstract}

Kata Kunci: Durio, steroid, lignan, kumarin

\begin{abstract}
Abstrack
Phytochemical investigation of secondary metabolites from the acetone extract of the wood of Durio oxleyanus Griff has obtained a steroid androst-1,4-dien-3,7-dion (1) together with two lignan compounds boehmenan (2), boehmenan X (3) and fraxidin (4). The chemical structures of the isolated compounds were identified on the basis of spectroscopic data and comparison with those data previously reported.
\end{abstract}

Keywords: Durio, steroid, lignan, coumarin<smiles>C[C@]12C=CC(=O)C=C1CCC1C2[CH]C[C@]2(C)C(=O)CC[C@@H]12</smiles>

(1)<smiles>COc1cc2ccc(=O)oc2c(O)c1OC</smiles><smiles>[R]c1cc(/C=C/C(=O)OC[C@H]2c3cc([C+]CCOC(=O)/C=C/c4ccc(O)c(OC)c4)cc(OC)c3O[C@@H]2c2ccc(O)c(OC)c2)ccc1O</smiles>

Gambar 1. Beberapa senyawa hasil ekstraksi dari Kayu Batang Durio oxleyamus 


\section{PENDAHULUAN}

Durio (durian) adalah satu satu genus tumbuhan yang banyak ditemukan di daerah Asia Tenggara khususnya Indonesia. Tumbuhan ini memiliki 28 spesies, 19 diantaranya tumbuh subur di hutan tropis Kalimantan (Subhadrabandhu, 2001) dan hanya delapan spesies menghasilkan buah yang dapat dimakan oleh manusia (Brown, 1997; Morton, 1987). Selain menghasilkan buah-buahan, kayu dari tumbuhan Durio dapat dimanfaatkan sebagai bahan bangunan terutama interior.

Selain dikenal sebagai penghasil buahbuahan, beberapa bagian dari tumbuhan Durio dapat digunakan sebagai obat tradisional. Kulit batang tumbuhan kerantungan (D. oxleyanus) biasa digunakan untuk mengobati penyakit malaria, sedangkan kulit batang tumbuhan $D$. griffitii mengandung tanin yang efektif untuk mengobati penyakit diare (Michon dan de Foresta, 1995; Uji, 2005). Nurliani dan Santoso (2010) juga telah melaporkan bahwa ekstrak kulit batang tumbuhan $D$. zibethinus dapat digunakan sebagai antifertilitas.

Kandungan senyawa utama dari buah tumbuhan Durio yang menimbulkan aroma yang khas adalah senyawa-senyawa sulfur seperti metil etil disulfida, benzotiazol dan dimetil sulfon (Weenan et al., 1996). Senyawa $\alpha$-tokoferol (Candlish, 1983), asam lemak palmitat, oleat (Moser et al., 1980) serta pektin (Hokputsa, 2004) juga telah diidentifikasi dari buah dan biji tumbuhan $D$. zibethinus.

Durio oxleyanus (durian hijau) merupakan salah satu spesies yang tumbuh endemik dan merupakan tumbuhan langka Indonesia yang tumbuh di pulau Kalimantan dan Sumatera (Uji, 2005). Penelitian sebelumnya terhadap ekstrak kulit batang tumbuhan $D$. oxleyanus telah dihasilkan senyawa-senyawa lignan, boehmenan $\mathrm{X}$, eritrocarolignan $\mathrm{X}$, treo-carolignan $\mathrm{X}$, eritrocarolignan $\mathrm{Y}$ dan treo-carolignan $\mathrm{Y}$ (Rudiyansyah, 2010).

Berkaitan dengan penelitan kami sebelumnya mengenai kandungan senyawasenyawa metabolit sekunder yang dihasilkan oleh tumbuhan Durio (Rudiyansyah, 2006 dan
2010), maka pada kesempatan ini kami melaporkan penemuan senyawa steroid, lignan dan turunan kumarin dari ekstrak aseton kayu batang tumbuhan D. oxleyanus. Struktur kimia senyawa-senyawa tersebut telah ditetapkan berdasarkan data spektra ${ }^{1} \mathrm{H}$-NMR, ${ }^{13} \mathrm{C}$-NMR dan MS serta dibandingkan dengan data literatur.

\section{METODE PENELITIAN}

Umum. Spektrum HRESIMS diukur menggunakan spektrometer Finnigan MAT 900 XL. Sampel untuk MS dipersiapkan pada konsentrasi $10 \mu \mathrm{M} / \mathrm{mL}$. Putaran optik $[\alpha]_{\mathrm{D}}$ direkam pada spektropolarimeter Jasco-P2000. Spektrum ${ }^{1} \mathrm{H}$ dan ${ }^{13} \mathrm{C}$ NMR dianalisis menggunakan Bruker Avance 400 dan Bruker Avance 500. Analisis data ${ }^{1} \mathrm{H}$ dan ${ }^{13} \mathrm{C}$ NMR diukur menggunakan sinyal residu pelarut terhadap $\mathrm{CDCl}_{3}(\delta=7,24 \mathrm{ppm})$ dan metanol- $d_{4}$ $(\delta=3,30 \mathrm{ppm})$. Kromatografi Cair Vakum (KCV) dilakukan menggunakan silika gel (Merck Kieselgel $60 \mathrm{H}$ ) dan Kromatografi Kolom dilakukan menggunakan silika gel Merck (230-400 Mesh). Kromatografi preparatif menggunakan plat KLT preparatif (Analtech Kieselgel $60 \mathrm{~F}_{254}, 20 \times 20 \mathrm{~cm}, 2 \mathrm{~mm}$ ). Analisis KLT pada plat (Merck Kieselgel $60 \mathrm{~F}_{254}$ atau $\left.\mathrm{RP}-18 \mathrm{~F}_{254 \mathrm{~s}}, 20 \times 20 \mathrm{~cm}, 0,25 \mathrm{~mm}\right)$. Noda pada KLT ditampakkan dengan sinar UV pada $\lambda_{254}$ dan $\lambda_{366} \mathrm{~nm}$ serta menggunakan penampak noda serium sulfat $15 \%$.

Bahan tumbuhan. Kayu batang tumbuhan D. oxleyanus Griff. diperoleh pada tahun 2007 dari hutan di Kabupaten Bengkayang Kalimantan Barat. Spesimen tumbuhan diidentifikasi oleh Staf dan disimpan di Herbarium Bogoriense, Bogor dengan nomor 864/IPH.1.02/If.8/2007.

Ekstraksi dan isolasi. Sampel serbuk kayu batang $(4 \mathrm{~kg})$ dimaserasi dalam pelarut aseton selama $3 \times 24$ jam sehingga diperoleh ekstrak aseton 98 g. Ekstrak aseton total kemudian dilarutkan dalam campuran metanol:air (95:5) yang selanjutnya dipartisi secara berturut-turut dengan pelarut $n$-heksana dan $\mathrm{CHCl}_{3}$. Fraksi kloroform yang dihasilkan sebanyak 32 g kemudian difraksinasi dengan 
kromatografi cair vakum. Pelarut yang digunakan untuk mengelusi $\mathrm{KCV}$ adalah $n$ heksana:etil asetat (7:3 - 0:10, metanol 100\%, masing-masing fraksi $150 \mathrm{~mL}$ ) sehingga dihasilkan 5 fraksi $\left(\mathrm{O}_{1}-\mathrm{O}_{5}\right)$. Sebanyak $1,2 \mathrm{~g}$ fraksi $\mathrm{O}_{3}$ fraksi yang terelusi oleh hasil $\mathrm{KCV}$ difraksinasi lebih lanjut dengan menggunakan kromatografi kolom tekan (flash column chromatography) dihasilkan 17 fraksi. Fraksi $\mathrm{O}_{3}-4$ dimurnikan dengan KLT preparatif menggunakan pelarut $\mathrm{CHCl}_{3}: \mathrm{MeOH}$ (99:1) sehingga diperoleh senyawa $1 \quad(5,5 \mathrm{mg})$. Senyawa fraksidin $4(2,2 \mathrm{mg})$ diperoleh dari fraksi $\mathrm{O}_{3}-2$ melalui pemurnian dengan KLT preparatif menggunakan pelarut $\mathrm{CHCl}_{3}: \mathrm{MeOH}$ (95:5). Senyawa lignan 2 dan 3 diisolasi dari fraksi $\mathrm{O}_{5}(9,4 \mathrm{~g})$. Kromatografi kolom tekan dilakukan terhadap fraksi $\mathrm{O}_{5}$ dengan menggunakan pelarut $n$-heksana:etil asetat (7:3 - 3:7, EtOAc $100 \%$, metanol $100 \%$, masingmasing fraksi $150 \mathrm{~mL}$ ) sehingga dihasilkan 12 fraksi. Terhadap fraksi $\mathrm{O}_{5^{-}} 7(98 \mathrm{mg})$ dilakukan kromatografi kolom tekan sehingga diperoleh senyawa boehmenan $2(15,9 \mathrm{mg})$ dan senyawa boehmenan X 3 (2,5 mg).

Androst-1,4-dien-3,7-dion diperoleh berupa padatan putih dengan nilai $[\alpha]_{D}^{23}+106,4^{\circ}\left(\mathrm{CHCl}_{3}\right)$; literatur (Faramarzi, 2006) $[\alpha]_{\mathrm{D}}+117^{\mathrm{O}}\left(\mathrm{CHCl}_{3}\right)$; Data ${ }^{1} \mathrm{H}-\mathrm{NMR}$ $\left(\mathrm{CDCl}_{3}, 500 \mathrm{MHz}\right)$, lihat Tabel 1; Data ${ }^{13} \mathrm{C}$ NMR $\left(\mathrm{CDCl}_{3}, 100 \mathrm{MHz}, \mathrm{DEPT}\right)$, lihat Tabel 2; HRESIMS $\left(\mathrm{m} / \mathrm{z}, 307,1674,[\mathrm{M}+\mathrm{Na}]^{+}\right)$, hitungan untuk $\mathrm{C}_{19} \mathrm{H}_{24} \mathrm{O}_{2} \mathrm{Na}, 307,1674$.

Boehmenan (2), diperoleh berupa padatan berwarna kuning, data ${ }^{1} \mathrm{H}-\mathrm{NMR}$ (metanol- $d_{4}, 500 \mathrm{MHz}$ ), lihat Tabel 3; data ${ }^{13} \mathrm{C}$ NMR (metanol- $d_{4}, 100 \mathrm{MHz}$ ), lihat Tabel 4; HRESIMS $\left(\mathrm{m} / \mathrm{z}, 735,2422,[\mathrm{M}+\mathrm{Na}]^{+}\right)$, hitungan untuk $\mathrm{C}_{40} \mathrm{H}_{40} \mathrm{O}_{12} \mathrm{Na}, 735,2418$.

Boehmenan X (3), diperoleh berupa padatan berwarna kuning, data ${ }^{1} \mathrm{H}-\mathrm{NMR}$ (metanol- $d_{4}, 500 \mathrm{MHz}$ ), lihat Tabel 5 ; data ${ }^{13} \mathrm{C}$ NMR (metanol- $d_{4}, 100 \mathrm{MHz}$ ), lihat Tabel 6; LRESIMS $\left(\mathrm{m} / z \quad 705,2, \quad[\mathrm{M}+\mathrm{Na}]^{+}\right)$, hitungan untuk $\mathrm{C}_{39} \mathrm{H}_{38} \mathrm{O}_{11} \mathrm{Na} 705,2$.

Fraksidin (4), diperoleh berupa padatan berwarna putih, data ${ }^{1} \mathrm{H}-\mathrm{NMR}\left(\mathrm{CDCl}_{3}, 500\right.$ MHz), lihat Tabel 7; LRESIMS ( $\mathrm{m} / \mathrm{z} 245,1$, $\left.[\mathrm{M}+\mathrm{Na}]^{+}\right)$, hitungan untuk $\mathrm{C}_{11} \mathrm{H}_{10} \mathrm{O}_{5} \mathrm{Na}, 245,0$.

\section{HASIL DAN PEMBAHASAN}

Senyawa 1 telah dimurnikan sebagai padatan putih dengan berat molekul $\mathrm{m} / \mathrm{z}$ 284,1674 yang sebanding dengan rumus molekul $\mathrm{C}_{19} \mathrm{H}_{24} \mathrm{O}_{2}$ sehingga memiliki derajat ketidakjenuhan sebesar 8 . Spektrum ${ }^{13} \mathrm{C}$-NMR (Tabel 1) menunjukkan adanya 19 sinyal karbon yang meliputi 2 karbonil $\left(\delta_{\mathrm{C}} 219,9\right.$ dan 186,2 ppm), 3 karbon kuarterner $\left(\delta_{\mathrm{C}} 168,2,47,7\right.$ dan $43,4 \mathrm{ppm}), 6$ karbon metin $\left(\delta_{\mathrm{C}} 155,2,127,7\right.$, $124,2,52,3,50,4$ dan 35,1 ppm), 6 karbon metilen $\left(\delta_{\mathrm{C}} 35,6,32,5,32,3,31,2,22,1\right.$ dan 21,9 ppm), dan 2 karbon metil $\left(\delta_{\mathrm{C}} 18,7\right.$ dan 13,8 ppm). Berdasarkan data ${ }^{13} \mathrm{C}-\mathrm{NMR}$ dan derajat ketidakjenuhan tersebut dapat disarankan bahwa senyawa 1 memiliki kerangka struktur kimia steroid.

Spektrum ${ }^{1} \mathrm{H}-\mathrm{NMR} \quad$ (Tabel 1) memperkuat adanya kerangka senyawa steroid dengan munculnya 2 gugus metil yaitu pada $\delta_{\mathrm{H}}$ $1,26 \mathrm{ppm}(\mathrm{s})$, dan $\delta_{\mathrm{H}} 0,95 \mathrm{ppm}$ (s). Tiga sinyal proton karakteristik untuk ikatan rangkap dua muncul pada geseran kimia $\delta_{\mathrm{H}} 7,04 \mathrm{ppm}(\mathrm{d}, J=$ $10,1 \mathrm{~Hz}, \mathrm{H}-1), \delta_{\mathrm{H}} 6,24$ (dd, $J=1,7 ; 10,1 \mathrm{~Hz}, \mathrm{H}-$ 2) dan sinyal proton pada $\delta_{\mathrm{H}} 6,09 \mathrm{ppm}(\mathrm{d}, J=$ $1,7 \mathrm{~Hz}, \mathrm{H}-4)$ menunjukkan adanya sistem diena tidak terkonyugasi yang berada pada satu cincin. Berdasarkan data ${ }^{1} \mathrm{H}-\mathrm{NMR},{ }^{13} \mathrm{C}-\mathrm{NMR}$ dan angka ketidakjenuhan dapat diketahui bahwa struktur kimia senyawa steroid 1 terdiri dari 2 karbonil, 2 ikatan rangkap dua serta 4 cincin.

Berdasarkan data tersebut serta dukungan data dari MS, senyawa 1 identik dengan androst-1,4-dien-3,7-dion dengan nama trivialnya boldion. Senyawa steroid ini baru pertama kali diisolasi dari tumbuhan Durio. Jenis senyawa steroid yang juga pernah diisolasi adalah $\beta$-sitosterol dan 3- $\beta$-hidroksi-21normetil-19-vinilidenilursan (Venkatesh et al., 2010) dari buah tumbuhan D. zibethinus. Senyawa 1 juga telah ditemukan dari beberapa tumbuhan seperti pada Scenedesmus quadricauda dan Acremonium strictum (DellaGreca, 1996; Faramarzi, 2006) Senyawa 2 diperoleh sebagai padatan berwarna kuning. Data HRESIMS memberikan sinyal $\mathrm{m} / \mathrm{z}$ 
Tabel 1. Data geseran kimia $(\delta){ }^{1} \mathrm{H}-\mathrm{NMR}$ dan ${ }^{13} \mathrm{C}-\mathrm{NMR}$ senyawa 1 dan boldion

\begin{tabular}{ccccccc}
\hline Posisi & $\begin{array}{c}\delta_{\mathrm{H}}(\mathrm{mult} ., \\
J \mathrm{~Hz})^{\mathrm{a}}\end{array}$ & $\delta_{\mathrm{H}}(\text { mult. })^{\mathrm{b}}$ & $\begin{array}{c}\delta_{\mathrm{H}}(\mathrm{mult} ., \\
J \mathrm{~Hz})^{\mathrm{c}}\end{array}$ & $\begin{array}{c}\delta^{13} \mathrm{C} \\
(\mathrm{ppm})^{\mathrm{a}}\end{array}$ & $\begin{array}{c}\delta^{13} \mathrm{C} \\
(\mathrm{ppm})^{\mathrm{b}}\end{array}$ & $\begin{array}{c}\delta^{13} \mathrm{C} \\
(\mathrm{ppm})^{\mathrm{c}}\end{array}$ \\
\hline 1 & $7,04(\mathrm{~d}, 10,1)$ & $7,03(\mathrm{~d})$ & $7,07(\mathrm{~d}, 10 \mathrm{~Hz})$ & 155,2 & 155,3 & 155,2 \\
2 & $6,24(\mathrm{dd}, 10,1 ; 1,7)$ & $6,24(\mathrm{dd})$ & $6,23(\mathrm{~d}, 10 \mathrm{~Hz})$ & 127,7 & 127,7 & 127,6 \\
3 & - & - & - & 186,2 & 186,2 & 186,0 \\
4 & $6,09(\mathrm{~d}, 1,7)$ & $6,06(\mathrm{~d})$ & $6,08(\mathrm{~s})$ & 124,2 & 124,1 & 124,0 \\
5 & - & - & - & 168,2 & 168,3 & 168,2 \\
6 & - & - & - & 32,3 & 32,3 & 32,3 \\
7 & - & - & - & 31,2 & 31,2 & 31,2 \\
8 & - & - & - & 52,3 & 52,3 & 52,3 \\
9 & - & - & - & 35,1 & 35,1 & 35,6 \\
10 & - & - & - & 43,3 & 43,4 & 43,4 \\
11 & - & - & - & 22,1 & 22,1 & 22,0 \\
12 & - & - & - & 32,5 & 32,6 & 32,5 \\
13 & - & - & - & 47,7 & 47,7 & 47,6 \\
14 & - & - & - & 50,4 & 50,4 & 50,4 \\
15 & - & - & - & 21,9 & 21,9 & 21,8 \\
16 & - & - & - & 35,6 & 35,6 & 35,5 \\
17 & - & - & - & 219,9 & 219,9 & 219,6 \\
18 & $0,94(\mathrm{~s})$ & $0,92(\mathrm{~s})$ & $0,94(\mathrm{~s})$ & 13,8 & 13,8 & 13,8 \\
19 & $1,25(\mathrm{~s})$ & $1,24(\mathrm{~s})$ & $1,25(\mathrm{~s})$ & 18,7 & 18,7 & 18,7 \\
\hline
\end{tabular}

${ }^{a}$ senyawa 1 dalam $\mathrm{CDCl}_{3}$ dari Durio oxleyanus

${ }^{\mathrm{b}}$ senyawa boldion dari Scenedesmus quadricauda (DellaGreca, 1996)

${ }^{\mathrm{c}}$ senyawa boldion dari Acremonium strictum (Faramarzi, M. A., 2006)

712,2422 yang sebanding dengan rumus molekul $\mathrm{C}_{40} \mathrm{H}_{40} \mathrm{O}_{12}$ sehingga memiliki derajat ketidakjenuhan sebesar 21. Sinyal karakteristik dari ${ }^{1} \mathrm{H}-\mathrm{NMR}$ (Tabel 2) untuk dua sistem transferuloil muncul pada $\delta_{\mathrm{H}} 7,44 \mathrm{ppm}(1 \mathrm{H}, \mathrm{d}, J=$ $\left.16,0 \mathrm{~Hz}, \mathrm{H}-7^{\prime \prime}\right), \delta_{\mathrm{H}} 6,25 \mathrm{ppm}(1 \mathrm{H}, \mathrm{d}, J=16,0$ $\left.\mathrm{Hz}, \mathrm{H}-8{ }^{\prime \prime \prime}\right), \delta_{\mathrm{H}} 7,10 \mathrm{ppm}(1 \mathrm{H}, \mathrm{d}, J=2,0 \mathrm{~Hz}, \mathrm{H}-$ $2^{\prime \prime \prime)}, \delta_{\mathrm{H}} 6,77 \mathrm{ppm}(2 \mathrm{H}, \mathrm{d}, J=7,5 \mathrm{~Hz}, \mathrm{H}-5$ "' dan $\mathrm{H}-5), \delta_{\mathrm{H}} 7,00 \mathrm{ppm}(1 \mathrm{H}, \mathrm{dd}, J=2,0 ; 7,5 \mathrm{~Hz}, \mathrm{C}-$ $\left.6{ }^{\prime \prime}\right)$ dan pada $\delta_{\mathrm{H}} 7,40 \mathrm{ppm}(1 \mathrm{H}, \mathrm{d}, J=16,0 \mathrm{~Hz}$, H-7), $\delta_{\mathrm{H}} 6,22 \mathrm{ppm}(1 \mathrm{H}, \mathrm{d}, J=16,0 \mathrm{~Hz}, \mathrm{H}-8), \delta_{\mathrm{H}}$ $7,04 \mathrm{ppm}(1 \mathrm{H}, \mathrm{d}, J=2,0 \mathrm{~Hz}, \mathrm{H}-2), \delta_{\mathrm{H}} 6,95 \mathrm{ppm}$ $(1 \mathrm{H}, \mathrm{dd}, J=2,0 ; 7,5 \mathrm{~Hz}, \mathrm{H}-6)$. Data ${ }^{1} \mathrm{H}-\mathrm{NMR}$ tersebut sebanding dengan derajat ketidakjenuhan sebesar 10, karena terdiri dari 2 cincin aromatik dan 2 sistem alkena yang berorientasi trans.

Lebih lanjut, dua sinyal proton metin aromatik yang berorientasi meta muncul pada $\delta_{\mathrm{H}} 6,76 \mathrm{ppm}\left(1 \mathrm{H}\right.$, br s, H-2") dan $\delta_{\mathrm{H}} 6,73 \mathrm{ppm}$ $(1 \mathrm{H}, \mathrm{d}, J=1 \mathrm{~Hz}, \mathrm{H}-6 ")$. Hal ini memperlihatkan bahwa cincin aromatik tersebut tersubstitusi pada posisi 1,3,4 dan 5. Terdapat juga tiga sinyal proton metilen yang saling berhubungan sebagai sistem ABM pada $\delta_{\mathrm{H}} 2,65 \mathrm{ppm}(2 \mathrm{H}, \mathrm{t}, J$ $=7,3 \mathrm{~Hz}, \mathrm{H}-7 "), \delta_{\mathrm{H}} 1,95 \mathrm{ppm}\left(2 \mathrm{H}, \mathrm{m}, \mathrm{H}-8^{\prime \prime}\right)$ dan $\delta_{\mathrm{H}} 4,13 \mathrm{ppm}(2 \mathrm{H}, \mathrm{m}, \mathrm{H}-9 ")$. Dua sinyal proton metin muncul pada $\delta_{\mathrm{H}} 5,34 \mathrm{ppm}(1 \mathrm{H}, \mathrm{d}, J=8,0$ $\left.\mathrm{Hz}, \mathrm{H}-7^{\prime}\right)$ dan $\delta_{\mathrm{H}} 3,78 \mathrm{ppm}\left(1 \mathrm{H}, \mathrm{m}, \mathrm{H}-8^{\prime}\right)$ bersama dengan dua sinyal proton geminal pada $\delta_{\mathrm{H}} 4,49 \mathrm{ppm}(1 \mathrm{H}, \mathrm{dd}, J=5,1 ; 11,0 \mathrm{~Hz}, \mathrm{H}-9$ 'a) dan $\delta_{\mathrm{H}} 4,36 \mathrm{ppm}(1 \mathrm{H}, \mathrm{dd}, J=7,9 ; 11.0 \mathrm{~Hz}, \mathrm{H}-$ 9 'b). Tiga sinyal proton untuk cincin aromatik tersubstitusi 1,3 dan 4 ditunjukkan pada $\delta_{\mathrm{H}} 6,92$ $\operatorname{ppm}\left(1 \mathrm{H}, \mathrm{d}, J=2,0 \mathrm{~Hz}, \mathrm{H}-2^{\prime}\right), \delta_{\mathrm{H}} 6,76 \mathrm{ppm}(1 \mathrm{H}$, $\mathrm{d}, J=8,0 \mathrm{~Hz}, \mathrm{H}-5)$ dan $\delta_{\mathrm{H}} 6,82 \mathrm{ppm}(1 \mathrm{H}, \mathrm{dd}, J$ $\left.=2,0 ; 8,0 \mathrm{~Hz}, \mathrm{H}-6{ }^{\prime}\right)$. Data-data ${ }^{1} \mathrm{H}-\mathrm{NMR}$ tersebut menunjukkan adanya sistem aril benzofuran yang juga merupakan kerangka dasar struktur senyawa lignan yang memiliki derajat ketidakjenuhan sebesar 9. Empat sinyal proton metoksi ditunjukkan pada $\delta_{\mathrm{H}} 3,83,3,82$, 3,80 dan 3,73 ppm.

Data spektrum ${ }^{13} \mathrm{C}-\mathrm{NMR}$ (Tabel 2) menunjukkan adanya 40 karbon termasuk dua gugus karbonil (derajat ketidakjenuhan sebesar 
2) pada $\delta_{\mathrm{C}} 169,2 \mathrm{ppm}\left(\mathrm{C}-9^{\prime \prime}\right), \delta_{\mathrm{C}} 168,7 \mathrm{ppm}(\mathrm{C}-$ 9), dan empat gugus metoksi pada $\delta_{C} 56,7,56,6$, 56,5 dan 56,4 ppm. Berdasarkan data ${ }^{1} \mathrm{H}-\mathrm{NMR}$ dan ${ }^{13} \mathrm{C}-\mathrm{NMR}$ di atas dapat diketahui bahwa senyawa 2 adalah golongan lignan dengan nama boehmenan. Konfigurasi relatif struktur senyawa 2 ditentukan sebagai trans didasarkan pada nilai kopling konstan $\left({ }^{3} J_{\mathrm{HH}}\right)$ yaitu $8,0 \mathrm{~Hz}$.
Senyawa 2 telah diisolasi sebelumnya dari ekstrak kulit batang tumbuhan $D$. zibethinus, $D$. carinatus dan D. oxleyanus (Rudiyansyah, 2006; 2010).

Senyawa 3 berhasil dimurnikan sebagai padatan kuning dengan rumus formula $\mathrm{C}_{39} \mathrm{H}_{38} \mathrm{O}_{11}$ berdasarkan data LRESIMS. Sinyalsinyal ${ }^{1} \mathrm{H}-\mathrm{NMR}$ (Tabel 3) senyawa 3 memiliki

Tabel 2. Perbandingan ${ }^{1} \mathrm{H}-\mathrm{NMR} \&{ }^{13} \mathrm{C}-\mathrm{NMR}$ senyawa 2 dengan boehmenan

\begin{tabular}{|c|c|c|c|c|}
\hline Posisi & $\begin{array}{c}\delta_{\mathrm{H}}(\text { mult. } \\
J \mathrm{~Hz})^{\mathrm{a}}\end{array}$ & $\begin{array}{c}\delta_{\mathrm{H}}(\text { mult. } \\
J \mathrm{~Hz})^{\mathrm{b}}\end{array}$ & $\begin{array}{c}\delta^{13} \mathrm{C} \\
(\mathrm{ppm})^{\mathrm{a}}\end{array}$ & $\begin{array}{c}\delta^{13} \mathrm{C} \\
(\mathrm{ppm})^{\mathrm{b}}\end{array}$ \\
\hline 1 & - & - & 127,5 & 127,5 \\
\hline 2 & $7,08(1 \mathrm{H}, \mathrm{d}, 2,0)$ & $7,05(1 \mathrm{H}, \mathrm{d}, 2,1)$ & 111,7 & 111,7 \\
\hline 3 & - & - & 149,3 & 149,3 \\
\hline 4 & - & - & 150,8 & 150,6 \\
\hline 5 & $6,79(1 \mathrm{H}, \mathrm{d}, 7,5)$ & $6,76(1 \mathrm{H}, \mathrm{d}, 8,0)$ & 116,5 & 116,5 \\
\hline 6 & $6,98(1 \mathrm{H}, \mathrm{dd}, 2,0 ; 7,5)$ & $6,95(1 \mathrm{H}, \mathrm{dd}, 2,1 ; 8,0)$ & 124,2 & 124,2 \\
\hline 7 & $7,41(1 \mathrm{H}, \mathrm{d}, 16,0)$ & $7,40(1 \mathrm{H}, \mathrm{d}, 16,0)$ & 147,2 & 147,2 \\
\hline 8 & $6,25(1 \mathrm{H}, \mathrm{d}, 16,0)$ & $6,21(1 \mathrm{H}, \mathrm{d}, 16,0)$ & 115,0 & 115,0 \\
\hline 9 & - & - & 168,8 & 168,8 \\
\hline $1^{\prime}$ & - & - & 133,7 & 133,7 \\
\hline $2^{\prime}$ & $6,92(1 \mathrm{H}, \mathrm{d}, 2,0)$ & $6,91(1 \mathrm{H}, \mathrm{d}, 2,0)$ & 111,0 & 110,6 \\
\hline $3^{\prime}$ & - & - & 149,0 & 149,1 \\
\hline $4^{\prime}$ & - & - & 147,8 & 147,8 \\
\hline $5^{\prime}$ & $6,76(1 \mathrm{H}, \mathrm{d}, 8,0)$ & $6,74(1 \mathrm{H}, \mathrm{d}, 8,0)$ & 116,2 & 116,2 \\
\hline $6^{\prime}$ & $6,82(1 \mathrm{H}, \mathrm{dd}, 2,0 ; 8,0)$ & $6,80(1 \mathrm{H}, \mathrm{dd}, 2,0 ; 8,0)$ & 120,3 & 121,0 \\
\hline $7^{\prime}$ & $5,36(1 \mathrm{H}, \mathrm{d}, 8,0)$ & $5,35(1 \mathrm{H}, \mathrm{d}, 8,3)$ & 90,2 & 90,2 \\
\hline $8^{\prime}$ & $3,78(1 \mathrm{H}, \mathrm{m})$ & $3,76(1 \mathrm{~J}, \mathrm{~m})$ & 51,8 & 51,9 \\
\hline $9^{\prime} \mathrm{a}$ & $4,52(1 \mathrm{H}, \mathrm{dd}, 5,0 ; 11,0)$ & $4,50(1 \mathrm{H}, \mathrm{dd}, 5,0 ; 11,0)$ & & \\
\hline $9^{\prime} \mathrm{b}$ & $4,37(1 \mathrm{H}, \mathrm{dd}, 7,5 ; 11,0)$ & $4,35(1 \mathrm{H}, \mathrm{dd}, 7,4 ; 11,0)$ & 66,6 & 66,6 \\
\hline $1 "$ & - & - & 136,5 & 136,5 \\
\hline $2^{\prime \prime}$ & $6,76(1 \mathrm{H}$, br s $)$ & $6,74(1 \mathrm{H}$, br s $)$ & 114,3 & 114,3 \\
\hline $3 "$ & - & - & 145,4 & 145,4 \\
\hline $4^{\prime \prime}$ & - & - & 147,6 & 147,6 \\
\hline $5^{\prime \prime}$ & - & - & 129,0 & 129,0 \\
\hline $6 "$ & $6,73(1 \mathrm{H}, \mathrm{d}, 1,0)$ & $6,70(1 \mathrm{H}$, br s $)$ & 120,3 & 120,3 \\
\hline $7^{\prime \prime}$ & $2,69(2 \mathrm{H}, \mathrm{t}, 7,5)$ & $2,66(2 \mathrm{H}, \mathrm{t}, 7,5)$ & 33,3 & 33,3 \\
\hline $8^{\prime \prime}$ & $1,99(2 \mathrm{H}, \mathrm{m})$ & $1,95(2 \mathrm{H}, \mathrm{t}, 7,5)$ & 31,7 & 31,7 \\
\hline $9 "$ & $4,16(2 \mathrm{H}, \mathrm{m})$ & $4,14(2 \mathrm{H}, \mathrm{t}, 7,5)$ & 65,0 & 65,0 \\
\hline $1^{\prime \prime \prime}$ & - & - & 127,6 & 127,7 \\
\hline $2^{\prime \prime \prime}$ &, $13(1 \mathrm{H}, \mathrm{d}, 2,0)$ & $7,10(1 \mathrm{H}, \mathrm{d}, 2,0)$ & 111,8 & 111,8 \\
\hline $3 " \prime$ & - & - & 149,0 & 149,3 \\
\hline $4^{\prime \prime \prime}$ & - & - & 150,6 & 150,5 \\
\hline $5^{\prime \prime \prime}$ & $6,79(1 \mathrm{H}, \mathrm{d}, 7,5)$ & $6,77(1 \mathrm{H}, \mathrm{d}, 7,8)$ & 116,5 & 116,5 \\
\hline $6^{\prime \prime \prime}$ & $7,02(1 \mathrm{H}, \mathrm{dd}, 2,0 ; 7,5)$ & $7,01(1 \mathrm{H}, \mathrm{dd}, 2,0 ; 7,8)$ & 124,0 & 124,0 \\
\hline $7^{\prime \prime \prime}$ & $7,47(1 \mathrm{H}, \mathrm{d}, 16,0)$ & $7,46(1 \mathrm{H}, \mathrm{d}, 16,0)$ & 146,6 & 146,6 \\
\hline $8^{\prime \prime \prime}$ & $6,27(1 \mathrm{H}, \mathrm{d}, 16,0)$ & $6,26(1 \mathrm{H}, \mathrm{d}, 16,0)$ & 115,5 & 115,5 \\
\hline 9"' & - & - & 169,2 & 169,2 \\
\hline OMe-3 & $3,85(3 \mathrm{H}, \mathrm{s})$ & $3,82(3 \mathrm{H}, \mathrm{s})$ & 56,5 & 56,4 \\
\hline OMe-3" & $3,83(3 \mathrm{H}, \mathrm{s})$ & $3,80(3 \mathrm{H}, \mathrm{s})$ & 56,7 & 56,7 \\
\hline OMe-3"' & $3,86(3 \mathrm{H}, \mathrm{s})$ & $3,83(3 \mathrm{H}, \mathrm{s})$ & 56,5 & 56,5 \\
\hline OMe-3' & $3,76(3 \mathrm{H}, \mathrm{s})$ & $3,73(3 \mathrm{H}, \mathrm{s})$ & 56.4 & 56,3 \\
\hline
\end{tabular}


Tabel 3. Perbandingan ${ }^{1} \mathrm{H}-\mathrm{NMR} \&{ }^{13} \mathrm{C}-\mathrm{NMR}$ senyawa 3 dengan boehmenan $\mathrm{X}$

\begin{tabular}{|c|c|c|c|c|}
\hline Posisi & $\delta_{\mathrm{H}}(\text { mult., } J \mathrm{~Hz})^{\mathrm{a}}$ & $\delta_{\mathrm{H}}(\text { mult., } J \mathrm{~Hz})^{\mathrm{b}}$ & $\delta^{13} \mathrm{C}(\mathrm{ppm})^{\mathrm{a}}$ & $\delta^{13} \mathrm{C}(\mathrm{ppm})^{\mathrm{b}}$ \\
\hline 1 & - & - & 127,0 & 126,5 \\
\hline 2 & $7,37(1 \mathrm{H}, \mathrm{d}, 8,6)$ & $7,36(1 \mathrm{H}, \mathrm{d}, 8,5)$ & 131,3 & 131,3 \\
\hline 3 & $6,76(1 \mathrm{H}, \mathrm{d}, 8,6)$ & $6,75(1 \mathrm{H}, \mathrm{d}, 8,5)$ & 116,8 & 117,2 \\
\hline 4 & - & - & 161,4 & 162,3 \\
\hline 5 & $6,76(1 \mathrm{H}, \mathrm{d}, 8,6)$ & $6,75(1 \mathrm{H}, \mathrm{d}, 8,5)$ & 116,8 & 117,2 \\
\hline 6 & $7,37(1 \mathrm{H}, \mathrm{d}, 8,6)$ & $7,36(1 \mathrm{H}, \mathrm{d}, 8,5)$ & 131,3 & 131,3 \\
\hline 7 & $7,43(1 \mathrm{H}, \mathrm{d}, 16,0)$ & $7,43(1 \mathrm{H}, \mathrm{d}, 15,9)$ & 147,0 & 147,2 \\
\hline 8 & $6,23(1 \mathrm{H}, \mathrm{d}, 16,0)$ & $6,21(1 \mathrm{H}, \mathrm{d}, 15,9)$ & 114,3 & 114,2 \\
\hline 9 & - & - & 168,8 & 168,9 \\
\hline $1^{\prime}$ & - & - & 133,7 & 133,7 \\
\hline $2^{\prime}$ & $6,92(1 \mathrm{H}, \mathrm{d}, 1,9)$ & $6,92(1 \mathrm{H}, \mathrm{d}, 1,8)$ & 110,9 & 110,9 \\
\hline $3^{\prime}$ & - & - & 149,1 & 149,1 \\
\hline $4^{\prime}$ & - & - & 147,8 & 147,8 \\
\hline $5^{\prime}$ & $6,77(1 \mathrm{H}, \mathrm{d}, 8,0)$ & $6,76(1 \mathrm{H}, \mathrm{d}, 8,2)$ & 116,2 & 116,2 \\
\hline $6^{\prime}$ & $6,83(1 \mathrm{H}, \mathrm{dd}, 1,9 ; 8,0)$ & $6,82(1 \mathrm{H}, \mathrm{dd}, 1,8 ; 8,2)$ & 120,2 & 120,2 \\
\hline $7^{\prime}$ & $5,37(1 \mathrm{H}, \mathrm{d}, 7,4)$ & $5,38(1 \mathrm{H}, \mathrm{d}, 7,4)$ & 90,1 & 90,1 \\
\hline $8^{\prime}$ & $3,79(1 \mathrm{H}, \mathrm{m})$ & $3,78(1 \mathrm{H}, \mathrm{m})$ & 51,9 & 51,9 \\
\hline $9^{\prime} \mathrm{a}$ & $4,52(1 \mathrm{H}, \mathrm{dd}, 5,0 ; 11,0)$ & $4,52(1 \mathrm{H}, \mathrm{dd}, 5,1 ; 11,0)$ & & \\
\hline $9^{\prime} \mathrm{b}$ & $4,37(1 \mathrm{H}, \mathrm{dd}, 7,5 ; 11,0)$ & $4,36(1 \mathrm{H}, \mathrm{dd}, 7,9 ; 11,0)$ & 66,6 & 66,6 \\
\hline $1 "$ & - & - & 136,6 & 136,6 \\
\hline $2^{\prime \prime}$ & $6,76(1 \mathrm{H}$, br s $)$ & $6,77(1 \mathrm{H}$, br s $)$ & 114,4 & 114,4 \\
\hline $3 "$ & - & - & 145,4 & 145,4 \\
\hline $4^{\prime \prime}$ & - & - & 147,6 & 147,6 \\
\hline $5 "$ & - & - & 129,0 & 129,0 \\
\hline $6^{\prime \prime}$ & $6,74(1 \mathrm{H}$, br s $)$ & $6,74(1 \mathrm{H}$, br s $)$ & 117,7 & 117,7 \\
\hline $7^{\prime \prime}$ & $2,70(2 \mathrm{H}, \mathrm{t}, 7,2)$ & $2,70(2 \mathrm{H}, \mathrm{t}, 7,3)$ & 33,3 & 33,3 \\
\hline $8^{\prime \prime}$ & $2,01(2 \mathrm{H}, \mathrm{m})$ & $2,00(2 \mathrm{H}, \mathrm{m})$ & 31,7 & 31,7 \\
\hline $9^{\prime \prime}$ & $4,17(2 \mathrm{H}, \mathrm{m})$ & $4,17(2 \mathrm{H}, \mathrm{m})$ & 65,0 & 64,9 \\
\hline $1^{\prime \prime \prime}$ & - & - & 127,7 & 127,2 \\
\hline $2^{\prime \prime \prime}$ & $7,15(1 \mathrm{H}, \mathrm{d}, 1,9)$ & $7,13(1 \mathrm{H}, \mathrm{d}, 1,8)$ & 111,8 & 111,7 \\
\hline $3^{\prime \prime \prime}$ & - & - & 149,4 & 149,6 \\
\hline $4^{\prime \prime \prime}$ & - & - & 150,6 & 151,5 \\
\hline $5 " \prime$ & $6,78(1 \mathrm{H}, \mathrm{d}, 8,0)$ & $6,78(1 \mathrm{H}, \mathrm{d}, 8,1)$ & 116,5 & 116,7 \\
\hline $6^{\prime \prime \prime}$ & $7,02(1 \mathrm{H}, \mathrm{dd}, 1,9 ; 8,0)$ & $7,03(1 \mathrm{H}, \mathrm{dd}, 1,8 ; 8,1)$ & 124,0 & 124,2 \\
\hline $7^{\prime \prime \prime}$ & $7,48(1 \mathrm{H}, \mathrm{d}, 16,0)$ & $7,49(1 \mathrm{H}, \mathrm{d}, 15,9)$ & 146,7 & 146,8 \\
\hline $8^{\prime \prime \prime}$ & $6,28(1 \mathrm{H}, \mathrm{d}, 16,0)$ & $6,26(1 \mathrm{H}, \mathrm{d}, 15,9)$ & 115,5 & 115,1 \\
\hline $9^{\prime \prime \prime}$ & - & - & 169,3 & 169,4 \\
\hline OMe-3" & $3,84(3 \mathrm{H}, \mathrm{s})$ & $3,84(3 \mathrm{H}, \mathrm{s})$ & 56,7 & 56,7 \\
\hline OMe-3"' & $3,87(3 \mathrm{H}, \mathrm{s})$ & $3,86(3 \mathrm{H}, \mathrm{s})$ & 56,4 & 56,4 \\
\hline OMe-3' & $3,76(3 \mathrm{H}, \mathrm{s})$ & $3,76(3 \mathrm{H}, \mathrm{s})$ & 56,4 & 56,4 \\
\hline
\end{tabular}

asenyawa 3 dalam $\mathrm{CD}_{3} \mathrm{OD}$ dari Durio oxleyanus

benyawa boehmenan X dari D. carinatus (Rudiyansyah, 2010)

banyak kemiripan dengan senyawa 2 , kecuali dengan munculnya sinyal pada $\delta_{\mathrm{H}} 7,36 \mathrm{ppm}$ $\left(2 \mathrm{H}, \mathrm{d}, J=8,5 \mathrm{~Hz}, \mathrm{H}-2\right.$ dan H-6) serta $\delta_{\mathrm{H}} 6,75$ ppm $(2 \mathrm{H}, \mathrm{d}, J=8,5 \mathrm{~Hz}, \mathrm{H}-3$ dan $\mathrm{H}-5)$. Hanya terdapat tiga gugus metoksi yaitu pada $\delta_{\mathrm{H}} 3,87$ ppm (3H, s, OCH3-3"'), $\delta_{\mathrm{H}} 3,84 \mathrm{ppm}(3 \mathrm{H}, \mathrm{s}$, OCH3-3"), dan $\delta_{\mathrm{H}} 3,76 \mathrm{ppm}(3 \mathrm{H}, \mathrm{s}, \mathrm{OCH} 3-3$ '). Spektrum ${ }^{13} \mathrm{C}-\mathrm{NMR}$ (Tabel 3) senyawa 3 juga memperlihatkan dua sinyal karbonil pada $\delta_{\mathrm{C}}$ 169,3 dan $\delta_{\mathrm{C}} 168,8$ ppm. Berdasarkan hal tersebut dapat disimpulkan bahwa struktur senyawa 3 adalah boehmenan $\mathrm{X}$ dimana senyawa ini juga telah ditemukan sebelumnya dari ekstrak kulit batang tumbuhan $D$. carinatus dan D. oxleyanus (Rudiyansyah, 2010).

Senyawa 4 diisolasi sebagai padatan putih dengan nilai $\mathrm{m} / z$ 222,1 (LRESIMS) yang sesuai dengan rumus formula $\mathrm{C}_{11} \mathrm{H}_{10} \mathrm{O}_{5}$ dan memiliki derajat ketidakjenuhan sebesar 7 . Spektrum ${ }^{1} \mathrm{H}-\mathrm{NMR}$ (Tabel 4) menunjukkan 
Tabel 4. Data perbandingan $\delta_{\mathrm{H}}{ }^{1} \mathrm{H}-\mathrm{NMR}$ senyawa 4 dengan fraksidin

\begin{tabular}{cll}
\hline Posisi & \multicolumn{1}{c}{$\delta_{\mathrm{H}}(\text { mult., } J \mathrm{~Hz})^{\mathrm{a}}$} & $\delta_{\mathrm{H}}(\text { mult., } J \mathrm{~Hz})^{\mathrm{b}}$ \\
\hline 3 & $6,34(1 \mathrm{H}, \mathrm{d}, 9,5 \mathrm{~Hz})$ & $6,26(1 \mathrm{H}, \mathrm{d})$ \\
4 & $7,60(1 \mathrm{H}, \mathrm{d}, 9,5 \mathrm{~Hz})$ & $7,60(1 \mathrm{H}, \mathrm{d})$ \\
5 & $6,50(1 \mathrm{H}, \mathrm{s})$ & $6,44(1 \mathrm{H}, \mathrm{s})$ \\
OMe-6 & $3,89(3 \mathrm{H}, \mathrm{s})$ & $3,83(3 \mathrm{H}, \mathrm{s})$ \\
OMe-7 & $4,00(3 \mathrm{H}, \mathrm{s})$ & $3,91(3 \mathrm{H}, \mathrm{s})$ \\
\hline
\end{tabular}

${ }^{2}$ senyawa 4 dalam $\mathrm{CDCl}_{3}$ dari Durio oxleyanus

bsenyawa fraksidin dari Jatropha podagrica Hook (Rumzhum, 2012)

adanya dua sinyal doblet dengan nilai kopling konstan $(J=9,5 \mathrm{~Hz})$ masing-masing untuk satu proton pada $\delta_{\mathrm{H}} 7,60$ dan $\delta_{\mathrm{H}} 6,33 \mathrm{ppm}$ yang merupakan sinyal proton cis-alkena (derajat ketidakjenuhan sebesar 1). Terdapat satu sinyal singlet untuk proton aromatik pada $\delta_{\mathrm{H}} 6,49 \mathrm{ppm}$ yang mengindikasikan cincin aromatik tersubstitusi 1,2,3,4 dan 5 (derajat ketidakjenuhan sebesar 4). Dua sinyal proton singlet untuk gugus metoksi terlihat pada $\delta_{\mathrm{H}}$ 4,00 dan $\delta_{\mathrm{H}} 3,99 \mathrm{ppm}$. Berdasarkan data ${ }^{1} \mathrm{H}-$ NMR dan angka derajat ketidakjenuhan, diindikasikan bahwa senyawa 4 memiliki kerangka dasar struktur kumarin. Struktur kimia senyawa 4 selanjutnya dibandingkan dengan data ${ }^{1} \mathrm{H}-\mathrm{NMR}$ dari literatur (Rumzhum et al., 2012) sehingga dapat diketahui bahwa senyawa 4 adalah fraksidin. Senyawa 4 ini juga telah diisolasi dari ekstrak kulit batang tumbuhan $D$. zibethinus (Rudiyansyah, 2006).

\section{KESIMPULAN}

Pada penelitian ini telah diisolasi 4 senyawa dari $D$. oxleyanus, satu senyawa steroid, dua senyawa lignan serta satu senyawa turunan kumarin. Struktur senyawa dielusidasi berdasarkan data ${ }^{1} \mathrm{H}-\mathrm{NMR},{ }^{13} \mathrm{C}-\mathrm{NMR}$, MS serta dibandingkan dengan data spektroskopi dari literatur.

\section{UCAPAN TERIMA KASIH}

Ucapan terima kasih kami sampaikan Dikti, Kemdikbud atas bantuan hibah penelitian Program Academic Recharging (PAR 2011), Prof. Mary J Garson dan Graham McFarlane yang telah memberikan fasilitas untuk pengukuran spektra NMR dan MS. Terima kasih juga disampaikan kepada staf Herbarium
Bogoriense, Bogor, yang telah mengidentifiasi spesimen tumbuhan.

\section{Daftar Pustaka}

Candlish, J. K., 1983, Tocopherol content of some Southeast Asian foods, J. Agric. Food. Chem., 31, 166-168.

DellaGreca, M., Previtera, L., 1996, Bioconversion of 17b-hydroxy-17a-methyl-androsta-1,4dien-3-one and Androsta-1,4-dione in cultures of the green alga T76 Scenedesmus quadricauda, Tetrahedron, 52, 13981-13990.

Faramarzi, M. A., Yazdi, M. T., Jahandar, H., Amini, M., Monsef-Esfahani, H. R., 2006, Studies onthe microbial transformation of androst1,4-dien-3,17-dione with Acremonium strictum, J. Ind Microbiol Biotechnol, 33, 725-733.

Hokputsa, S., Gerddit, W., Pongsamart, S. I. K., Heinze, T., Koschella, A., Harding, S. E., Paulsen, B. S., 2004, Water-soluble polysaccharides with pharmaceutical importance from Durian rinds (Durio zibethinus Murr.): isolation, fractionation, characterisation and bioactivity, Carbohydrate Polymers, 56, 471-481.

Michon, G., de Foresta, H., 1995, The Indonesian Agroforest Model. Forest fesource management and biodiversity conservation in P. Halladay and D.A Gilmour Eds, Conservation biodiversity outside protected areas. The role of traditional agro-ecosystem, IUCN.

Moser, R., Duvel, D., Greve, R., 1980, Volatile constituents of durian (Durio zibethinus Murr.), Phytochemistry, 19, 79-81.

Nowshin N. Rumzhum, Md. Hossain Sohrab, Muhammad Abdullah Al-Mansur, Mohammad S. Rahman, Choudhury M. Hasan and Mohammad A. Rashid, 2012, Secondary metabolites from Jatropha 
podagrica Hook, Journal of Physical Science, 23, 29-37.

Nurliani, A., Santoso, H.B., 2010, Efek spermatisida ekstrak kulit kayu Durian (Durio zibethinus Murr.) terhadap mortilitas dan kecepatan gerak spematozoa manusia secara In Vitro, Sains dan terapan Kimia, 4:72.

Rudiyansyah., Garson, M. J., Secondary Metabolites from the Wood Bark of Durio zibethinus and Durio kutejensis, Journal of Natural Product, 2006, 69, 1218-1221.

Rudiyansyah., Lambert, L. K., Garson, M. J., Lignans and Triterpenes from the Bark of
Durio carinatus and Durio oxleyanus, Journal of Natural Product, 2010, 73, 1649-1654

Subhadrabandhu, S.; Ketsa, S., 2001, Durian king of tropical fruit; CABI publisher: Wellington, NZ.

Uji, T., 2005, Keanekaragaman jenis dan sumber plasma nutfah Durio (Durio spp.) di Indonesia, Bulletin plasma nutfah, 11:28.

Weenan, H.; Koolhass, W. E.; Apriyantono, A., 1996, Sulfur-containing volatiles of Durian fruits (Durio zibethinus Murr.), J. Agric.
Food
Chem.,
44 ,
3291-3293 